\title{
Interação Social no Autismo em Ambientes Digitais de Aprendizagem
}

\author{
Social Interaction in Austim in Learning Virtual Environment
}

\author{
Liliana Maria Passerino* \& Lucila Costi M. Santarosa** \\ Universidade Federal do Rio Grande do Sul, Porto Alegre, Brasil
}

\begin{abstract}
Resumo
O objetivo deste artigo é discutir sobre o desenvolvimento da interação social em ambientes digitais de aprendizagem, com sujeitos com Autismo. A revisão de literatura baseia-se na Teoria Sócio-Histórica e em teóricos do Autismo. Para tanto, parte-se de uma discussão mais ampla sobre Interação Social e seu desenvolvimento, assim como as características apresentadas no autismo, considerando a intencionalidade de comunicação como um dos principais construtos teóricos para análise da interação social de pessoas com autismo em ambientes digitais. Finalmente, apresentamos e discutimos dados coletados num estudo de caso com quatro sujeitos com diferentes níveis da síndrome que foi realizado ao longo de dois anos de pesquisa utilizando ambientes digitais diversos, assim como os resultados alcançados no estudo.

Palavras-chave: Interação social; autismo; ambientes digitais de aprendizagem.
\end{abstract}

\begin{abstract}
The goal of this paper is to discuss the development of social interactions in virtual environments, specially considering the autism. The literature review is based on Sociohistorical Theory and main theoretical works about this condition. We start from a wide discussion about social interaction, its development and relation to autism characteristics, considering that the concept of intentional communication is fundamental to the analysis of social interaction of autistic subjects in virtual environments. Furthermore, we present and discuss the data obtained from a case of study carried out with four subjects that suffer from different levels of autism. The study was developed as a two years of research applying several virtual environments. We also discuss the main results of this research.

Keywords: Autism; social interaction; virtual learning environment.
\end{abstract}

Muitos são os estudos focados na interação social em ambientes digitais, principalmente após a expansão considerável da Internet. Porém, a questão da interação social permanece aberta em termos de como analisar e compreender esse fenômeno. Em especial, são poucos os estudos envolvendo a interação social em ambientes digitais com pessoas com autismo. Nesse sentido, somente um estudo foi identificado no qual se pretendia desenvolver skills de comunicação em crianças e jovens com Síndrome de Asperger utilizando uma ferramenta de bate papo (comunicação síncrona) apoiada com esquemas de comunicação (skills). Mas, lamentavelmente, esse estudo foi descontinuado sem resultados concretos (Orlich, 2003).

A maioria dos estudos vinculados à questão do uso de novas tecnologicas da informação e comunicação e o autismo, ficam restritos ao desenvolvimento de softwares específicos para o tratamento de algum aspecto particular do transtorno (Barth, Passerino \& Santarosa, 2004; Center for Spoken Language Research at the University of Colorado [CSLR], 2003; Gil \& Orts, 2003; Gutierrez, 1999;

\footnotetext{
Endereço para correspondência: Av. Paulo Gama, 110 - Prédio 12105 - $3^{\circ}$ andar - sala 334, Porto Alegre, RS, 90040-060. Fone: (051) 3308-3070. E-mail: liliana@pgie.ufrgs.br; liliana@cinted.ufrgs.br

** Endereço para correspondência: Av. Paulo da Gama, s/n, Prédio 12201, Sala 308, Porto Alegre, RS, 9004-6900. Fone/Fax: (051) 3308-3269. E-mail: lucila.santarosa@ufrgs.br
}

Hanson et al., 2005; Heinman \& Tjus, 1999; International Business Machines [IBM], (n.d.); Picard, 2000; Piconi \& Tanaka, 2002, Silver \& Oakes, 2001). Assim, não existem pesquisas e estudos que abordem especificamente o déficit na interação social no autismo a partir do uso de tecnologias de informação e comunicação.

No presente trabalho apresentamos os principais resultados de uma pesquisa de campo na qual foram analisados os aspectos mencionados acima: interação social no autismo mediada em ambientes digitais. Os resultados obtidos mostram possibilidades no uso da tecnologia como tratamento terapêutico, embora o principal objetivo do presente estudo não vise definir um procedimento terapêutico, senão identificar padrões de interação social quando mediados por tecnologia a fim de estabelecer possibilidades de uso e aplicação de ambientes digitais como forma de promover a interação social em pessoas com autismo. Com essa finalidade, iniciamos nossa explanação partindo da concepção de interação social e dos déficits apresentados no autismo, para posteriormente apresentar o cenário da nossa pesquisa propriamente dita e os resultados obtidos na mesma.

\section{Interação Social}

Do ponto de vista etimológico, a palavra interação social sugere a idéia de ação entre sujeitos, ou “. . . ação conjunta e interdependente de dois ou mais participantes e que produz mudanças tanto nos sujeitos como no contexto no quala 
interação se desenvolve” (Watzlawick, Beavin \& Jackson, 1967, p. 108). Alguns autores, porém, a definem a partir da sua funcionalidade como sendo “... o veículo fundamental para a transmissão dinâmica do conhecimento cultural e histórico" (Garton, 1994, p. 22) ou do ponto de vista sistêmico como "um sistema aberto sujeito a contínuas mudanças e adaptações durante o processo interativo" (Bosa, 2002, p. 3). Como podemos perceber, a interação social é uma relação complexa que envolve um grande número de variáveis. Com o presente trabalho procuramos ampliar a compreensão desse fenômeno a partir da sua manifestação num público específico, reconhecido pelo seu déficit na mesma, ou seja, analisando o fenômeno da Interação Social com relação à Síndrome de Autismo e especificamente na manifestação da interação promovida em ambientes digitais por ser esta uma área na qual existem poucas pesquisas como mencionamos antes.

Partimos, da concepção de interação social de Vygotsky (1998) que a considera o motor do do desenvolvimento cognitivo humano, sendo este último resultado de processos de mediação simbólica que acontecem na criação e uso de signos dentro do contexto de interação social de forma intencional e voluntária por parte dos sujeitos. Assim, o símbolo ou signo, na teoria sócio-histórica, representa um objeto, físico ou não, cujo significado foi constituído pela sociedade e tem por função ser mediador da atividade interna dirigida para o controle do próprio indivíduo. Para Wertsch (1999) a atividade humana só pode ser entendida se consideramos esses signos e sua forma de utilização (mediação). Cabe destacar que as formas de mediação não são concebidas como fatores que facilitam a atividade, mas, a configuram e a definem através do controle progressivo do sujeito sobre o signo e que geralmente é denominado de internalização. Para Vygotsky (1998), o processo de internalização pode ser observado a partir de uma série de transformações:

1. A operação que representa uma atividade externa é reconstruída e começa a ocorrer internamente.

2. Um processo interpessoal é transformado num processo intrapessoal.

3. A transformação de um processo interpessoal num intrapessoal é o resultado de uma longa série de eventos ocorridos durante o desenvolvimento.

É importante salientar que a internalização é um processo de controle sobre os signos externos, e não um processo de cópia ou de imitação (Wertsch, 1988), "um processo de desenvolvimento e aprendizagem humana como incorporação da cultura, como domínio de modos culturais de agir, pensar, de se relacionar com outros, consigo mesmo e que aparece como contrário a uma perspectiva naturalista ou inatista" (Smolka, 2000, p. 27-28). Na internalização são particularmente importantes os símbolos lingüísticos, pois, incorporam historicamente a forma como nossos antepassados acharam necessário categorizar e interpretar o mundo visando principalmente a comunicação interpessoal. Esta significação sócio-histórica nos libera da percepção imediata ao permitir projetar-nos no tempo e no espaço criando representações mentais simultâneas do mesmo fenômeno. Desta forma, um signo como ferramenta psicológica é orientado para agir sobre o sujeito em dois sentidos: social e culturalmente. Cultural porque foi desenvolvido num processo histórico-cultural como ferramenta cultural, e social, pois seu uso e aplicação é sempre dentro de uma atividade cultural numa interação social (Wertsch, 1988).

Essa atividade cultural mediada por signos constituídos e internalizados na interação social evidencia-se principalmente na participação dos sujeitos em interações triádicas. A interação triádica (sujeito-objeto-sujeito) acontece quando existe uma coordenação de interações entre sujeitos e objetos resultando num triângulo referencial entre o sujeito A, o sujeito B e o objeto e/ou evento ao qual prestam atenção. Estas relações triádicas recebem o nome genérico de Atenção Conjunta, e representam um processo complexo de interação social. Para Tomasello (2003) as cenas de atenção conjunta só são possíveis quando as crianças começam perceber os outros como agentes intencionais iguais a ela. Um agente intencional é definido como ". . . seres comuns que possuem objetivos e fazem escolhas ativas entre os meios comportamentais disponíveis para atingir aqueles objetivos, o que inclui escolher ativamente a que se vai prestar atenção na busca desses objetivos" (p. 94-95).

Desta forma, as cenas de atenção conjunta são interações sociais nas quais os sujeitos prestam conjuntamente atenção a uma terceira pessoa/objeto por um período de tempo. Não são cenas perceptuais, pois focam alguns aspectos do mundo perceptual, não são eventos lingüísticos, pois contêm mais coisas do que é explícito nos símbolos lingüísticos. Numa cena de atenção conjunta os sujeitos precisam se identificar como agentes intencionais, ou seja ". . . fornecer o contexto intersubjetivo em que se dá o processo de interação” (Tomasello, 2003 p. 137). É pela compreensão das outras pessoas como agentes intencionais iguais a si mesmo que se criam

... (os) processos de sociogênese por meio dos quais vários indivíduos colaboram entre si para criar artefatos e práticas culturais . . e e, . . processos de aprendizagem cultural e internalização por meio dos quais indivíduos em desenvolvimento aprendem a usar e depois internalizam aspectos dos produtos criados pela colaboração entre co-específicos. (Tomasello, 2003, p. 19-20).

Então, as cenas de atenção conjunta não só permitem construção de artefatos e práticas culturais mas criam instrumentos/signos de mediação que permitem aprender as coisas "através" dos outros de forma que não apenas nos apropriamos desses artefatos e práticas, mas também dos problemas e situações para os quais foram desenvolvidos. Desta forma, os artefatos e práticas apontam para além deles mesmos (mundo físico) apontam para o mundo psicológico, das intenções e crenças, das representações mentais dos nossos pares conformando o que genericamente denominamos de processo de mediação (Tomasello, 2003; Vygotsky, 1998; Wertsch, 1988).

Dado que a interação social, então, promove e proporciona as condições necessárias para a mediação e que esta acon- 
tece sempre dentro de um processo de comunicação entre agentes intencionais, consideramos como requisito essencial à interação social, a existência da comunicação, sendo para tanto necessária uma forma de construção e representação de mensagens, ou seja, uma linguagem. No presente trabalho adotaremos a concepção de Vygotsky (2001) de linguagem, concebida como um sistema composto por um conjunto de símbolos e de normas, e com uma dupla função: permitir a construção de mensagens e, ser o mecanismo através do qual atribuímos significados de forma compartilhada, um mecanismo de construção de contextos sociais (Vygotsky, 1998). Portanto, a comunicação não pode ser considerada um processo linear e alternado de troca de mensagens, mas um processo interativo e intersubjetivo que implica no uso de um meio de comunicação, na construção de significados e na intencionalidade de comunicação, tornando-o um fenômeno relacional em que os sujeitos estão envolvidos numa dinâmica própria e regras específicas (implícitas ou explícitas) das quais nenhum dos sujeitos tem o domínio completo.

Resumindo, a Interação Social é uma relação complexa que se desenvolve com a participação não somente dos sujeitos diretamente envolvidos, mas dos instrumentos de mediação inseridos no contex to sócio-cultural ao qual tais sujeitos pertencem. A interação evidencia-se principalmente pela linguagem, mas também pelas ações dos sujeitos no plano interpessoal e pelas significações atribuídas a todos os elementos da relação, pelos participantes no plano intrapessoal. Segundo Tomasello (2003), é justamente pela percepção do outro como agente intencional que temos um dos principais requisitos para identificar a intencionalidade de comunicação e portanto a existência de interação social. Estes indícios constituem a fase denominada diádica do desenvolvimento da comunicação intencional (Bosa, 2002). Na fase posterior, denominada triádica verifica-se uma seqüência no desenvolvimento da comunicação composta por três categorias em ordem crescente de complexidade:

1. Afiliação: utilização de comportamentos não verbais para manter o foco da atenção em si mesmo.

2. Regulação: comportamento de pedido para busca de assistência quanto à aquisição de objetos ou execução de tarefas.

3. Atenção compartilhada: entendida como a coordenação da atenção entre os parceiros sociais com fins de compartilhar experiências com objetos e/ou eventos. Sendo esta a fase mais avançada da intencionalidade (Bosa, 2002).

Porém, a existência de intencionalidade, segundo Wertsch (1988), é possível ser identificada, também, através de outros indícios como: Nível de Abreviação Predicativa e Perspectiva referencial. Abreviação predicativa é a substituição do sujeito numa frase, permanecendo o predicado, mas mantendo o sujeito de forma implícita. Segundo Wertsch não são as palavras que levam a maior parte do significado, mas, o contex to que é construído no processo de interação social na medida que os interlocutores realizam um “intercâmbio verbal”, na qual a abreviação predicativa é um componente indispensável e que permitiria através dessas "chaves lingüísticas" ou signos contextualizados, elevar o contexto extralingüístico ao nível semântico da fala. Wertsch propõe utilizar a abreviação não apenas como indício da existência da fala interna, mas, como indício concreto do funcionamento interpsicológico ou da interação social real. Numa interação encontraremos a representação lingüística (diálogos) e a definição de situação (contex to extralingüístico), mantendo uma relação inversamente proporcional, isto é, quanto menos elementos da definição de situação encontram-se explícitos na fala, maior seu nível de abreviação. Um interlocutor irá produzir comunicações com informações explícitas quando compartilha poucos aspectos da definição da situação com o outro interlocutor, ou seja, quando o nível de intersubjetividade for baixo. Porém, se o nível de abreviação for alto e a fala não for dirigida ao interlocutor, mas dirigida ao próprio sujeito sem interesse de ser interpretado pelo outro, teremos um forte indício de comunicação não intencional. Portanto, abreviação predicativa será um indício duplo que tomará seu sentido em função do diálogo estabelecido e da definição de situação, não apenas considerando o sujeito como indivíduo, mas a dupla de interlocutores em interação é que determinarão o sentido da situação ter ou não uma intenção de comunicação.

Com relação à perspectiva referencial, Wertsch (1988) a define como um tipo de representação num ato referencial, “. . . é a perspectiva ou ponto de vista utilizado pelo falante para identificar um referente. Qualquer ato referencial supõe necessariamente uma perspectiva referencial” (p. 178). Assim, um ato de comunicação implica necessariamente num referente, e, portanto se localizarmos os referentes nas falas dos sujeitos participantes podemos identificar a existência de comunicação entre os mesmos. Wertsch em especial chama a atenção sobre um mecanismo semiótico denominado deixis. O uso adequado de deíticos (como "este" ou "aquele", por exemplo) pressupõe a existência cognitiva do referente para os interlocutores, e sua importância reside no fato de indicar um nível crescente de intersubjetividade e mostrar o funcionamento entre o inter e o intrapsicológico.

\section{Déficit da Interação Social no Autismo}

Neste item apresentamos uma breve revisão das principais pesquisas e estudos teóricos sobre a interação social no autismo de forma a construir uma articulação com o marco conceitual visto acima. O resultado disso é uma marco teórico diferenciado que foi utilizado na análise dos dados desta pesquisa e que encontra-se mais detalhado em Passerino (2005). Muitos autores consideram o déficit da interação social no autismo como sendo seu déficit primário. Entre eles encontramos duas linhas de pesquisa representadas respectivamente por Hobson (1993) e Baron-Cohen (1990), entre outros autores. Hobson considera que a característica principal do autismo é a limitação ou deficiência na sua capacidade de ter um "sentido da relação pessoal" e de experimentar essa relação, ou de criar um significado para a 
interação social e conseqüentemente participar da mesma. Por outro lado, Baron-Cohen considera que esta falha na "representação do ser pessoa" é devido a uma limitação na compreensão das crenças, ou seja, dos estados mentais das pessoas, genericamente denominado de Teoria da Mente. Como vemos, ambos concordam com relação à limitação da capacidade de compreensão dos estados mentais, mas discordam com o que consideram ser a causa desta limitação, pois segundo Hobson essa teria um caráter afetivo e não de capacidade de representação.

Especificamente sobre a Interação Social, Hobson (1993) afirma que para conhecer as pessoas é necessário entender e experimentar as relações sociais, ou seja, participar da interação social. Autênticas relações interpessoais levam a uma interação social plena quando existem intercâmbios recíprocos e coordenação de sentimentos que permitem o compartilhar uma experiência ou situação. Para Hobson (1993) uma interação social plena precisa da presença de dois requisitos fundamentais: dialogicidade e envolvimento afetivo. Somente com a presença destes requisitos é que acontece o fenômeno social de "compartilhar".

Com relação à atenção conjunta, um dos aspectos essenciais no estudo da interação social e que abordamos no item anterior, sujeitos com autismo raramente compartilham a atenção do parceiro ou mesmo do adulto sobre algum objeto ou evento particular. São incapazes de focar a atenção visual de forma espontânea com um adulto e atrair a atenção deste para realizarem juntos alguma tarefa, “... crianças autistas têm em geral pouca ou nenhuma estratégia para compartilhar a atenção com os outros" (Jordan \& Powell, 1995 , p. 18). Além disso, evitam o contato visual com freqüência, utilizando mais a percepção periférica do que a direta (Sigman \& Capps, 2000).

Com relação às características da interação social em sujeitos com autismo, Lorna Wing (1998), identificou quatro grupos diferenciados: Isolamento Social; Interação Passiva; Interação Ativa-porém-estranha e Interação Hiperformal. Todas estas categorias se diferenciam pelo grau de reciprocidade na interação estabelecida com outros sujeitos.

Retomando os aspectos destacados no item sobre a Interação Social, no qual consideramos que comunicação e a interação social como processos interdependentes, podemos verificar que os estudos de Wing (1998) e outros pesquisadores demonstram que no autismo a comunicação apresenta, também, limitações e anomalias. Na comunicação não verbal, encontramos ausência de intercâmbios corporais expressivos, na verbal, falta de intercâmbios coloquiais com falas não ajustadas no contexto, repetitivas e ecolálicas, inversão pronominal, e dificuldades no uso de abreviação predicativa e na compreensão de metáforas ou simbolismos (Hobson, 1993; Jordan \& Powell, 1995). Sendo estes últimos importantes para a existência de intencionalidade de comunicação como apresentamos no item anterior, e essenciais para a existência da relação de atenção conjunta. Pessoas com autismo, portanto, se comunicam e utilizam a linguagem de forma peculiar, não somente com relação à sua sintaxe e gramática, mas com relação à semântica e pragmática da comunicação, o que levaria a questionar a capacidade de estabelecer uma interação social de acordo com os pressupostos estabelecidos no item anterior e principalmente se a mesma se estabelece mediada através de tecnologias da comunicação e informação (Passerino, 2005).

Por esse motivo, na presente pesquisa procuramos utilizar ambientes digitais que oportunizassem a interação social dos sujeitos com autismo, observando o desenvolvimento desse processo. Para isso, optamos por um ambiente digital desenvolvido pelo Núcleo de Informática na Educação Especial - NIEE da Universidade Federal do Rio Grande do Sul (UFRGS) denominado EDUKITO. O mesmo foi idealizado e projetado como um Ambiente Digital de Aprendizagem (ADA) que permitisse o desenvolvimento de Projetos de Aprendizagem seguindo a concepção epistemológica embasada na Teoria Sócio-Histórica. Consideramos um Ambiente Digital de Aprendizagem (ADA), àquele que de acordo com Jonassen (1999) se constitue num espaço virtual no qual os sujeitos participam de um processo construtivista de ensino e aprendizagem, caracterizando-se por ser ativo, no sentido de permitir o controle do processo pelo aluno, construtivo, no sentido do aluno poder construir seus próprios modelos mentais e crenças com relação ao objeto em estudo, reflexivo propiciando espaço para a reflexão sobre a ação do aluno, complexo, evitando o conhecimento "fragmentado", contextualizado, pois aprender sobre algo, é aprender dentro de um contexto e colaborativo, propiciando o diálogo, a troca de experiências, o trabalho em grupo pela colaboração, a argumentação, o consenso e a discussão.

O ambiente EDUKITO diferencia-se de outros por ser um ambiente orientado a projetos de aprendizagem, no qual são disponibilizadas e integradas diferentes ferramentas de interação e comunicação, além de espaços para reflexão pessoal e organização de materiais desenvolvidos ao longo dos projetos pelos participantes (Passerino \& Santarosa, 2004).

Como pode ser visto na Figura 1, a estrutura do EDUKITO tem como elemento central a ferramenta que cria e disponibiliza Projetos. Para apoiar a organização do trabalho, foi criada a ferramenta Agenda. É ali que são publicadas as propostas de trabalho para um determinado projeto. A comunicação entre os participantes e o compartilhamento dos trabalhos desenvolvidos são pontos centrais no desenvolvimento de projetos e por isso são apoiados por ferramentas de comunicação e de colaboração como o Correio, Grupos, Recados, Diário, Bate-Papo, entre outros. Nesse ambiente, complementado com outras ferramentas computacionais gerais como editores de textos, de imagens, e ferramentas diversas é que desenvolvemos a pesquisa que descrevemos a seguir.

\section{Método}

A ênfase dada à compreensão do fenômeno coloca a presente pesquisa dentro de pressupostos qualitativos do estudo de caso visando compreender quais processos de interação social evidenciam-se em sujeitos com autismo utilizando ambientes digitais de aprendizagem. Apresentaremos o método adotado na pesquisa dividindo-o em duas seções: participantes e procedimentos. 


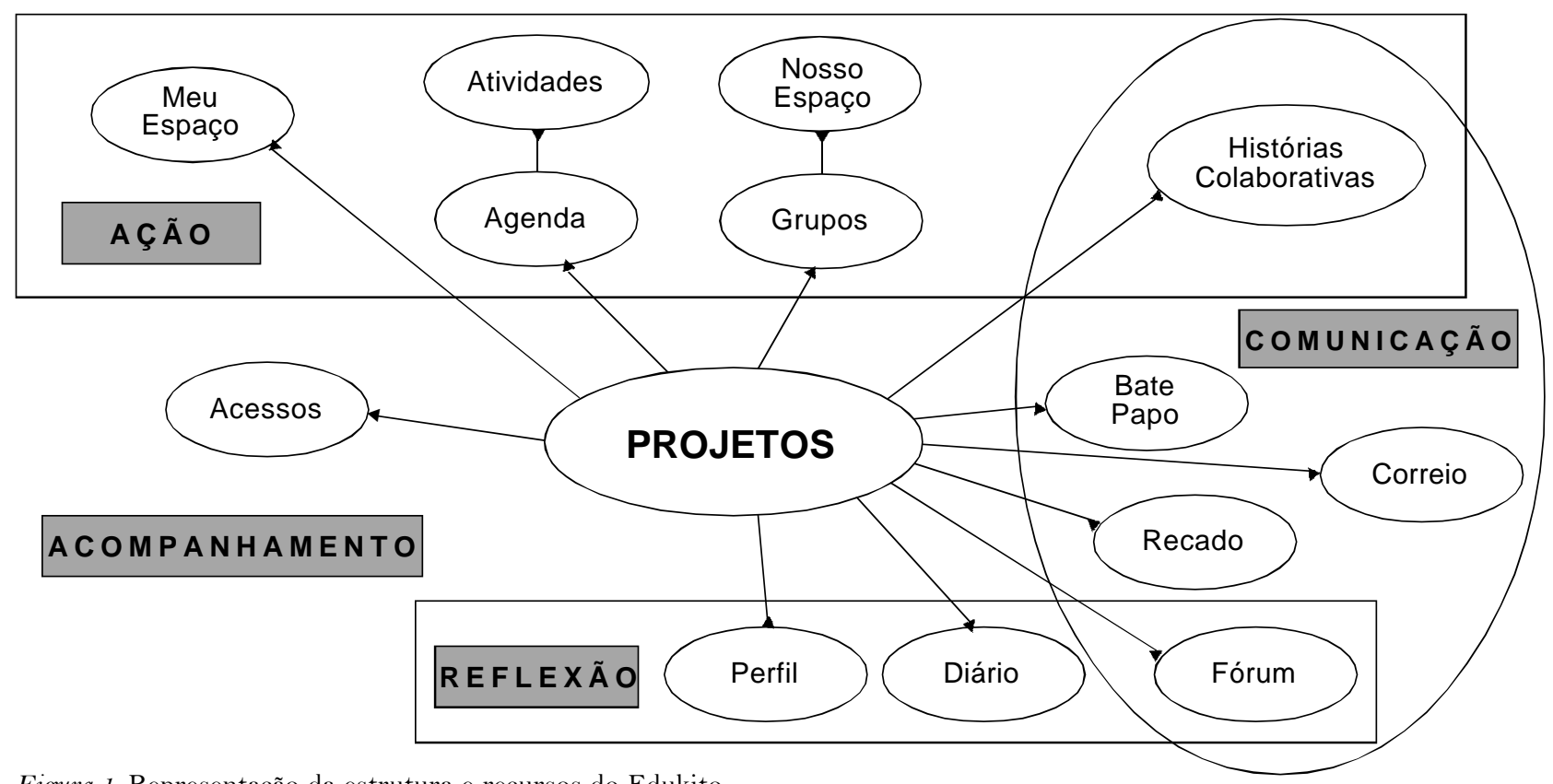

Figura 1. Representação da estrutura e recursos do Edukito.

\section{Participantes}

Como num estudo de caso os dados são de caráter predominantemente descritivo e a preocupação centra-se nos processos e não nos produtos, a seleção dos casos foi um ponto relevante deste estudo, assim como também o ambiente no qual se desenvolveria o mesmo. Dado que a pesquisa previa o trabalho em grupo foi selecionada uma instituição especializada em Transtornos Invasivos do Desenvolvimento que tivesse sujeitos com autismo. Do total de indivíduos da instituição foram selecionados quatro sujeitos com autismo em níveis diferenciados, do leve ao moderado, numa escolha intencional que procurou abranger o continuum do transtorno. A seleção foi baseada no diagnóstico realizado anteriormente por profissionais devidamente credenciados que utilizaram a escala The Childhood Autism Rating Scale ([CARS], Schopler et al., 1988) para diagnóstico dos mesmos. Os sujeitos cuja faixa etária variava entre 15 e 28 anos foram divididos em díades, que denominamos grupo 1 e 2 respectivamente. O grupo 1 foi composto pelos sujeitos alfabetizados, enquanto que no segundo grupo os sujeitos tinham iniciado algum processo de alfabetização. Cada díade foi acompanhada em sessões semanais de 2 a 3 horas de duração ao longo de 2 anos que se desenvolveram no laboratório de uma instituição especializada em Transtornos Invasivos do Desenvolvimento. Para estabelecer o perfil inicial dos participantes foi realizada observação in loco de 2 meses. Sinteticamente podemos colocar o perfil de cada sujeito como sendo:

1. Grupo 1 (autismo leve): sujeitos A. e M. O sujeito A. com 27 anos era alfabetizado com um nível de interação passivo e em raras situações reativo. O sujeito M. com 26 anos participava das interações de forma reativa, raramente iniciando um processo de interação, e com uma fala hiper-formal.
2. Grupo 2 (autismo moderado): sujeitos $\mathrm{A} 2$ e M2. O sujeito M2 tinha 15 anos e era totalmente isolado, com forte ecolalia e movimentos estereotipados. A2 com 28 anos apresentava ecolalia e algumas características de isolamento nas interações sociais.

\section{Procedimento}

A pesquisa contou com três etapas diferenciadas, uma primeira etapa de observação para avaliação inicial dos vários sujeitos, traçar um perfil dos mesmos e ajudar na seleção dos casos. Nesta etapa foram realizadas entrevistas com pais, professores e profissionais juntamente com análise documental de relatórios e diagnósticos médicos e educacionais disponíveis. Na segunda etapa, iniciamos o processo de observação-intervenção-coleta a partir das díades constituídas como mencionamos acima. O trabalho foi desenvolvido num laboratório de informática com computadores para cada aluno e a presença física somente da pesquisadora. Ao longo das sessões a metodologia de trabalho foi estabelecer e definir com os sujeitos participantes projetos de aprendizagem, nos quais os assuntos de interesse dos sujeitos foram contemplados. Cada sessão foi registrada e gravada em vídeo para posterior análise juntamente com os registros de campo. Além dessas técnicas de coleta, também foram utilizados os logs das interações desenvolvidas no ambiente digital.

A proposta de intervenção consistia em desenvolver com as díades trabalhos em grupo estruturados como projetos nos quais os próprios sujeitos participavam na escolha dos temas e na medida do possível também da definição dos objetivos e atividades que seriam realizadas. Cada sessão foi estruturada em quatro momentos. Num primeiro momento, em geral entre quinze a vinte minutos iniciais, a díade juntamente com a pesquisadora lembrava o que tinha sido realizado na sessão anterior e definia os objetivos 
e tarefas para esta. $\mathrm{O}$ segundo momento apresentava-se a ferramenta e/ou ambiente que seriam utilizados instruindo os sujeitos juntos sobre o uso de alguma tecnologia ou algum software para desenvolver as tarefas propostas. $\mathrm{O}$ tempo destinado a esta etapa podia variar de sessão para sessão dependendo da complexidade da ferramenta, dos conhecimentos prévios e das dificuldades de aprendizagem e compreensão dos próprios sujeitos. Podia até mesmo não ser necessária ou ocupar uma sessão completa. O terceiro momento era destinado ao trabalho individual e/ou interação com seu colega e outros sujeitos dentro do ambiente digital através das ferramentas de comunicação síncronas e assíncronas. Esta etapa abrangia a maior parte da sessão e nela a pesquisadora mantinha uma observação participante, intervindo somente nos momentos necessários ou solicitados. Por último, o quarto momento consistia novamente numa discussão com o grupo sobre o que tinha sido feito e sobre o que ficou para a próxima sessão.

Para análise e interpretação dos dados partiu-se dos pressupostos téoricos apresentados na seção sobre a Interação Social reorganizando os registros e confrontando-os com as transcrições das gravações e os $\log$. Desta forma, foi possível uma triangulação dos dados propiciando maior confiabilidade à presente pesquisa utilizando várias fontes de dados para melhor observar o fenômeno. (Stake, 1999). A análise embasada na Teoria sócio-histórica aconteceu em dois níveis: micro e macro. No nível macro, foi orientada para o contexto sócio-cultural das ações e centrou-se principalmente na interação social do grupo. No nível micro, orientou-se ao âmbito de ações dos indivíduos acompanhando a apropriação dos instrumentos e signos pelos sujeitos em interação. Este processo duplo de análise permitiu abordar o fenômeno em dois planos: interpessoal e intrapessoal.

\section{Resultados e Discussão dos Dados}

\section{Grupo 1}

Nas primeiras sessões identificamos pouca ou nenhuma existência de comunicação entre os sujeitos e destes com a pesquisadora. M. manteve uma troca pequena de perguntas enquanto A. não interagiu com a mesma mantendo-se passivo. A participação de M. foi do tipo reativa, obedecendo ao que a pesquisadora solicitava. Nenhum dos sujeitos estabeleceu uma interação real, pois inexistia uma intenção de comunicação (não possuíam nenhuma meta e não prestavam atenção ao meio). Com relação à abreviação predicativa ela é encontrada, representando um indício de falta de intenção na comunicação, já que os interlocutores envolvidos não tinham nenhum contex to compartilhado com o qual construir o sentido da comunicação. A perspectiva referencial também não foi utilizada pelos sujeitos. A partir da sessão 6 e 7 acontece uma mudança na interação de A. que deixa de ser passivo no seu nível de participação, e se transforma num sujeito reativo-ativo. Nestas sessões estabeleceu-se uma interação diádica como definida por Bosa (2002) na qual A. mostrou claramente possuir metas (embora definidas externamente pela mediadora) e agiu ativamente para atingilas, como vemos no seguinte exemplo:
L. - Como procuras na internet?

A. - Com o Terra.

L. - E qual mais?

A. - Cadê.

A. - [Depois de entrar no site ficou olhando como que esperando e finalmente perguntou]: Como começo?

L. - Procura em palavras chave [a pesquisadora não deu nenhum tipo de orientação gestual para esta fala direta].

A. - [Identificou rapidamente o local aonde iriam as palavras chave] O que escrevo?

L. - Coloca planetas ou sistema solar [ele digitou sistema solar].

A. - O que faço agora?

L. - Agora tens que escolher um planeta e procurar algumas informações dele. Por qual gostarias começar?

A. - Pelo sol.

L. - Vamos gravar imagens então para o nosso livro virtual e anotar algumas informações, ok?

A. - [Gravou as imagens sozinho sem problemas $]$.

Com relação a M. encontramos poucas mudanças no processo de interação, exceto talvez pelo fato de M. mostrar agora indícios de intenção de comunicação num nível diádico ao prestar atenção ao meio e compreender as metas das ações do outro, mas não mostrou ter metas próprias e nem agiu para atendê-las, de acordo com os critérios vistos.

M. - [Entra no correio e fica lendo as mensagens]

L. - Vás responder? ¿Referindo-me ao e-mail de uma menina do NIEE que escreveu para ele dentro do nosso ambiente]

M. -Vou. [M. aprende rápido, mas perde o interesse... parece sempre desligado letárgico].

M. - O que falo para ela?

L. - Não sei... O que posso falar para uma pessoa? De que elas gostam?

M. - Não sei.

L. - Do que tu gostas de falar?

M. - [Não responde]

L. - Então... De que gostas de falar?

M. - Sobre cinema.

L. - Então podes falar com K. sobre isso, o que K. te contou no seu e-mail? [M. volta para a tela do computador e lê a mensagem em voz alta para mim].

L. - O que ela gosta?

M. - Passear.

L. - Então quem sabe tu contas se tu gostas de passear? [M. fica agora concentrado escrevendo].

M. - Que mais escrevo?

L. - Podes dizer onde tu passeias.

M. - Não.

L. - Porque?

M. - Não quero. 
Um ponto importante que merece ser destacado é que, a mudança no nível de participação de A. mostrou-se definitiva, pois em todas as sessões seguintes ele manteve uma participação ativa na maioria das vezes e em algumas reativas. Por outro lado, a definição das metas para agir e tornar-se um agente intencional, ainda dependem do mediador:

A. - O que faremos hoje?

L. - Vamos continuar buscando material na internet sobre os planetas?

A. - Vamos. [Ficou aguardando].

L. - Ok, então onde é que nos encontrávamos na semana passada?

A. - No Terra. [Referindo-se ao site de busca, pensando em iniciar todo o processo de busca novamente].

L. - [A. abre o explorer e digita o endereço sem dificuldade. Para olhando a página carregar e espera...].

Vemos no trecho anterior o uso da abreviação predicativa por parte do sujeito A. quando responde a uma pergunta da mediadora, essa abreviação mostra intenção comunicativa, pois o sujeito está prestando atenção ao meio (no nosso caso lingüístico) e suas mudanças. Um aspecto interessante é que em nenhuma das sessões anteriores foi utilizada a perspectiva referencial pelos sujeitos participantes. Num outro exemplo de uma interação estabelecida agora entre a pesquisadora e o sujeito A. através de uma ferramenta assíncrona. A. age como agente intencional com uma meta clara (ver o filme) e age para consegui-la, insistindo sem no entanto explicitar sua intenção esperando que a pesquisadora interprete a sua mensagem:

Mensagem enviada por A. no dia 5/7:

vais ver o filme star wars episodio 2 o ataque dos clones ou ficaria fazendo o que em casa

Mensagem enviada por A. no dia 8/7:

Poderíamos ver os filmes star wars episodio 2 o ataque dos clones ou men in black 2 com will smith

Essa situação se repete em várias situações diferentes, parecendo que A. tem dificuldade em expressar seus desejos ou, o que acreditamos ser mais provável, não percebe o seu interlocutor (o outro agente) como intencional e que é possível que ele tenha metas diferentes das dele, sem poder extrair tais informações do contexto. Isto indicaria que A. tem dificuldade na construção de um intersubjetividade, pois de acordo com Tomasello (2003), seria necessário:

1. Perceber o outro como agente intencional.

2. Participar das cenas de atenção conjunta.

3. Compreender não apenas as intenções, mas as intenções comunicativas, nas que o outro sujeito quer que se preste atenção a algum evento/objeto numa cena de atenção conjunta.

4. Conseguir realizar a inversão de papéis.
Essa intersubjetividade, como definida por Wertsch (1988), acontece quando os interlocutores compartilham algum aspecto da definição de situação, através de cenas de atenção conjunta que partem do princípio da intencionalidade da comunicação vendo os parceiros como agentes intencionais iguais a si mesmo e construindo um processo de compartilhamento de perspectivas que passa por diferentes níveis. Podemos ver que o uso da abreviação predicativa por parte de A. pode ser um indício dessa dificuldade de tomada de consciência e da troca necessária de papéis numa interação social verdadeira restando poder informacional ao contex to interacional.

Com relação à fase triádica podemos afirmar que A. atingiu o nível de regulação, pois foi capaz de estabelecer comportamentos de pedidos de ajuda ou assistência para executar tarefas (como ir ao cinema, por exemplo). Alguns indícios de atenção compartilhada, embora restrita, que não estavam presente no início da pesquisa, foram encontrados nas últimas sessões.

Mensagem enviada no dia 6/11 pelo sujeito A.:

oi liliana

te mandei mais receitas pra ti querida liliana

tchau liliana

quanto ao filme poderia ser nesse fim de semana

Finalmente, verificamos que ao longo das sessões tanto o sujeito M. quanto A. desenvolveram um nível de interação cada vez maior. No caso de A. que iniciou como isolado, em poucas semanas passou para passivo e posteriormente reativo e, no final da pesquisa, ativo-porém-estranho como indicado por Wing (1998). M teve um desempenho semelhante, mas o mais destacado do processo de interação estudado, foi a evolução que ambos sujeitos tiveram em relação à existência de intencionalidade, chegando no final da pesquisa a mostrar indício de atenção compartilhada, como apresentamos na Tabela 1 (página seguinte).

\section{Grupo 2}

O grupo dois constituído por A2 e M2, como mostra a Tabela 2 (página seguinte), inicialmente pouco participativos, podendo classificá-los como passivos. Seu nível de interação também é baixo, sendo em geral do tipo isolado de acordo Wing (1998).

Ambos sujeitos mantiveram um comportamento estereotipado e ecolalia típicos da síndrome. Um exemplo da ecolalia de M2 pode ser visto no exemplo:

L. - Onde mora a coruja?

M2 - Onde mora a coruja.

L. - Ela voa ou caminha?

M2 - Caminha.

L. - Na água?

M2 - Na água.

A partir da sessão 11-12 verificamos mudanças em A2 e M2 principalmente com relação à intencionalidade que até o momento ficava na fase de afiliação passando para fase de 
Tabela 1

Síntese das Interações dos Sujeitos A e M

\begin{tabular}{|c|c|c|c|c|c|c|c|c|c|c|}
\hline SESSÃO & \multicolumn{2}{|c|}{ Sessão 1} & \multicolumn{2}{|c|}{ Sessão 5} & \multicolumn{2}{|c|}{ Sessão 6} & \multicolumn{2}{|c|}{ Sessão 7} & \multicolumn{2}{|c|}{ Sessão 23-25 } \\
\hline & M & $\mathrm{A}$ & $\mathrm{M}$ & A & $\mathrm{M}$ & $\mathrm{A}$ & $\mathrm{M}$ & $\mathrm{A}$ & $\mathrm{M}$ & A \\
\hline $\begin{array}{l}\text { Nível de } \\
\text { Participação }\end{array}$ & reativa & passiva & reativa & passiva & reativa & reativa & reativa & $\begin{array}{c}\text { reativa/ } \\
\text { ativo }\end{array}$ & ativo & ativo \\
\hline $\begin{array}{l}\text { Nível de } \\
\text { Interação }\end{array}$ & $\begin{array}{c}\text { passivo/ } \\
\text { ativo- } \\
\text { estranho }\end{array}$ & isolado & passivo & passivo & $\begin{array}{c}\text { ativo- } \\
\text { estranho }\end{array}$ & reativo & $\begin{array}{l}\text { hiper- } \\
\text { formal }\end{array}$ & $\begin{array}{c}\text { ativo- } \\
\text { estranho }\end{array}$ & $\begin{array}{c}\text { ativo- } \\
\text { estranho }\end{array}$ & $\begin{array}{c}\text { ativo- } \\
\text { estranho }\end{array}$ \\
\hline $\begin{array}{l}\text { Intenciona_ } \\
\text { lidade } \\
\text { Diádica }\end{array}$ & não & não & não & diádico & $\begin{array}{l}\text { diádico } \\
\text { (baixo) }\end{array}$ & $\begin{array}{l}\text { diádico } \\
\text { (baixo) }\end{array}$ & diádico & diádico & diádico & diádico \\
\hline $\begin{array}{l}\text { Intenciona- } \\
\text { lidade } \\
\text { Triádica }\end{array}$ & afiliação & afiliação & regulação & regulação & regulação & regulação & regulação & $\begin{array}{l}\text { afiliação } \\
\text { regulação }\end{array}$ & $\begin{array}{c}\text { atenção } \\
\text { compar- } \\
\text { tilhada }\end{array}$ & $\begin{array}{c}\text { regulação } \\
\text { compar- } \\
\text { tilhada }\end{array}$ \\
\hline $\begin{array}{l}\text { Perspectiva } \\
\text { Referencial }\end{array}$ & não & não & não & não & não & não & não & pouca & $\operatorname{sim}$ & $\operatorname{sim}$ \\
\hline $\begin{array}{l}\text { Abreviação } \\
\text { Predicativa }\end{array}$ & $\operatorname{sim}$ & não & $\operatorname{sim}$ & não & $\operatorname{sim}$ & $\operatorname{sim}$ & $\operatorname{sim}$ & $\operatorname{sim}($ alta $)$ & $\operatorname{sim}$ & $\operatorname{sim}$ \\
\hline
\end{tabular}

Tabela 2

Sintese das Interações dos Sujeitos A2 e M2

\begin{tabular}{|c|c|c|c|c|c|c|c|c|c|c|c|}
\hline \multirow[t]{2}{*}{ SESSÃO } & \multicolumn{3}{|c|}{$1-3$} & $9-11$ & \multicolumn{2}{|c|}{12} & \multicolumn{2}{|r|}{$14-21$} & \multicolumn{2}{|r|}{25} & \multirow{2}{*}{$\begin{array}{c}40-56 \\
\mathrm{M} 2 \\
\end{array}$} \\
\hline & $\mathrm{A} 2$ & $\mathrm{M} 2$ & $\mathrm{~A} 2$ & $\mathrm{M} 2$ & $\mathrm{~A} 2$ & $\mathrm{M} 2$ & $\mathrm{~A} 2$ & $\mathrm{M} 2$ & $\mathrm{~A} 2$ & $\mathrm{M} 2$ & \\
\hline $\begin{array}{l}\text { Nível de } \\
\text { Participação }\end{array}$ & passiva & passiva & passiva- & reativa & reativa & reativa & ativa & reativa & ativo & $\begin{array}{c}\text { reativo- } \\
\text { ativo }\end{array}$ & $\begin{array}{c}\text { quase- } \\
\text { ativo }\end{array}$ \\
\hline $\begin{array}{l}\text { Nível de } \\
\text { Interação }\end{array}$ & isolado & isolado & isolado & passivo & passivo & passivo & \begin{tabular}{|c|} 
ativo- \\
porém- \\
estranho
\end{tabular} & passivo & $\begin{array}{c}\text { ativo- } \\
\text { porém- } \\
\text { estranho }\end{array}$ & $\begin{array}{c}\text { ativo- } \\
\text { porém- } \\
\text { estranho }\end{array}$ & $\begin{array}{l}\text { ativo- } \\
\text { porém- } \\
\text { estranho }\end{array}$ \\
\hline $\begin{array}{l}\text { Intenciona- } \\
\text { lidade } \\
\text { - Diádica }\end{array}$ & não & não & não & parcial & não & parcial & não & parcial & $\begin{array}{c}\text { Sim } \\
\text { (possui } \\
\text { metas) }\end{array}$ & parcial & parcial \\
\hline $\begin{array}{l}\text { Intenciona- } \\
\text { lidade } \\
\text { Triádica } \\
\end{array}$ & não & afiliação & não & $\begin{array}{l}\text { regula- } \\
\text { ção }\end{array}$ & afiliação & $\begin{array}{l}\text { regula- } \\
\text { ção }\end{array}$ & $\begin{array}{l}\text { regula- } \\
\text { ção }\end{array}$ & afiliação & $\begin{array}{c}\text { atenção } \\
\text { compar- } \\
\text { tilhada } \\
\end{array}$ & $\begin{array}{l}\text { regula- } \\
\text { ção }\end{array}$ & $\begin{array}{l}\text { regula- } \\
\text { ção }\end{array}$ \\
\hline $\begin{array}{l}\text { Perspectiva } \\
\text { Referencial }\end{array}$ & não & não & não & $\operatorname{sim}$ & não & $\operatorname{sim}$ & não & não & $\operatorname{sim}$ & $\operatorname{sim}$ & não \\
\hline $\begin{array}{l}\text { Abreviação } \\
\text { Predicativa }\end{array}$ & ecolálica & ecolálica & ecolálica & $\operatorname{sim}$ & $\operatorname{sim}$ & $\operatorname{sim}$ & $\operatorname{sim}$ & ecolálica & $\operatorname{sim}$ & $\operatorname{sim}$ & $\operatorname{sim}$ \\
\hline
\end{tabular}

regulação, solicitando ajuda para realização de uma tarefa, mas sem iniciativa nem atenção compartilhada.

Fui mostrando cada ferramenta e como inserir objetos e A2 se mostrava empolgado dizendo:

A2 - Quero bola! [E a seguir fazia o procedimento de inserção, clicando e arrastando].

A2 - Quero boneco!

A2 - Quero balde! [E assim continuou colocando outros objetos].

L. - A2, porque não coloca os nomes desses objetos embaixo deles?
A2 - A2 coloca b com duas barriga. [E clicou no P e ficou esperando balançando].

L. - Ok a próxima letra?

A2 - O?

L. - Sim e agora?

A2 - L.

A2 - A?

L. - Sim isso mesmo, o que está escrito?

A2 - BOLA $\sqsubset$ Na verdade estava POLA, mas não foi corrigido]. 
No diálogo acima vemos que A2 não possui intenção de comunicação completa como analisada por Bosa (2002). O processo indica mais uma intencionalidade no nível triádico na forma de regulação, agindo quando solicitado, não tomando a iniciativa, mas efetuando todas as atividades propostas. M2 mantém o mesmo padrão de interação que mostramos aqui, de forma que nem A2 nem M2 agem como agentes intencionais, pois fracassam em pelo menos dois critérios para ter intencionalidade de comunicação: não percebem o outro como agente itencional, nem suas metas e não têm metas próprias. Com relação à abreviação predicativa, a mesma continua num nível ecolálico. Após praticamente dois meses de trabalho com os sujeitos, cada um mantém um trabalho isolado no seu computador. A2 tem passado por uma mudança importante, deixando de ser passivo para se tornar reativo-ativo, embora a sua participação ativa seja estranha como Wing (1998) relata nos seus estudos. Um ponto importante que devemos destacar é com relação à fala de A2, que passou a ser em primeira pessoa. Também nas atividades propostas A2 tem tomado a iniciativa na escolha dos objetos falando em voz alta e antecipadamente suas ações, já não se altera e tem parado parcialmente com os movimentos estereotipados, mantendo um maior nível de atenção. Na escrita A2 tem começado a escrever a partir do som, mas pede confirmação da pesquisadora para efetivamente digitar (como vimos no exemplo acima).

M2 que era totalmente isolado e passivo tem evoluído pouco, apenas para se tornar reativo. $\mathrm{Na}$ intencionalidade M2 permanece mais no nível de afiliação e como A2 também não age como um agente intencional. Mas na sessão 40 encontramos M2 mais ativo, com indício de intencionalidade, tendo uma meta e agindo de acordo com ela, prestando atenção ao meio e ao interlocutor com o qual manteve um diálogo ativo-porém-estranho:

L. - M2 vamos entrar no Google para pesquisar?

$\mathrm{M} 2$ - Vamos.

L. - Onde fica o Google, lembra?

M2 - Não lembra não.

L. - Então clica no ícone da internet [M2 clicou num ícone qualquer da tela dizendo: "Essa, essa...”].

L. - Onde clicamos quando queremos acessar a internet?

$\mathrm{M} 2$ - Ai, ai [novamente apontando numa pasta qualquer, por exemplo, meus documentos].

L. - Não... É azul e tem um E [M2 localiza visualmente e clica].

No exemplo anterior podemos observar que M2 participa das atividades de forma quase-ativa, pois têm interesse, e age em função dele. De acordo com os critérios estabelecidos para a intencionalidade de comunicação consideramos que M2 encontra-se na fase de regulação, na qual o comportamento característico dessa fase é a procura de ajuda para a execução de tarefas (Bosa, 2002). Obviamente a falta de apropriação da linguagem escrita pelos sujeitos, deste grupo, prejudicou bastante a apropriação de outros procedimentos embasados na linguagem. Com relação às categorias estabelecidas por Wertsch (1999) de abreviação predicativa e perspectiva referencial, $\mathrm{M} 2$, manteve ao longo da pesquisa um nível elevado de abreviação predicativa e praticamente nula perspectiva referencial, sendo que quando aparece está vinculada à regulação (pedido de ajuda) que o sujeito estabelece com a pesquisadora na resolução das tarefas.

Analisando a Tabela 2 percebemos que tanto M2 quanto A2 desenvolveram um nível de interação cada vez maior, embora não tenham atingido os níveis do grupo anterior. Esta situação era de certa forma esperada, pois os sujeitos do grupo 2 pertencem a um grau de autismo mais profundo. No caso de A2 que iniciou como isolado, em poucas semanas passou para passivo e posteriormente reativo, e acreditamos que se o sujeito tivesse continuado na nossa pesquisa poderíamos ter alcançado um nível ativo-porémestranho como indicado por Wing (1998). M2 teve um desempenho semelhante, mas o mais destacado do processo de interação de M2 é que em várias oportunidades foram percebidos avanços e retrocessos nesse processo. De forma geral, M2 teve uma leve melhoria na sua interação se comparado com o seu perfil inicial, mas mantém participação reativa esperando sempre pela ação da pesquisadora e comportamento estereotipado, com uma intencionalidade de comunicação na fase triádica, do tipo de regulação, solicitando ajuda e confirmação na resolução de tarefas.

\section{Considerações Finais}

Observando os dados sintetizados nas Tabelas 1 e 2 é possível perceber que a perspectiva referencial quando presente pode ser considerada como um forte indicativo de interação social na qual os participantes envolvem-se num processo real de trocas. Por outro lado, a presença de abreviação predicativa foi evidenciada mesmo sem indício de existência de intencionalidade. Aparentemente no autismo o uso de abreviação predicativa, não implica intencionalidade de comunicação, assumindo características de ecolalia, como forma de manter um processo de comunicação. Portanto, concluimos que não é possível considerar a presença de abreviação predicativa como um indício de interação social. Com relação à intencionalidade da comunicação, seu desenvolvimento foi evidenciado principalmente nos sujeitos do primeiro grupo. A falta de intencionalidade de comunicação evidenciada nos sujeitos do grupo dois pode estar relacionada com a falta de compreensão das metas das ações do outro, que é um dos requisitos para se tornar um agente intencional.

Com relação às categorias de interação indicadas por Wing (1998), encontramos indícios para uma nova categoria: a interação ecolálica, na qual a ecolalia não se limita a uma repetição sem sentido da fala do interlocutor, mas a uma repetição funcional que visa representar um questionamento ou uma solicitação de ajuda ou um pedido de confirmação do interlocutor. É claro que este é um indício que merece maiores pesquisas, mas nos exemplos que apresentamos principalmente de M2 a interação ecolálica 
parece ser a forma que este sujeito encontra de manter uma comunicação, embora estranha com seu interlocutor. Também percebemos que problemas na interação social podem estar mais vinculados à semântica a e pragmática da linguagem que à falta de intencionalidade. Existem rituais de início e fim de conversa, em pessoas com autismo, mas tais rituais são diferentes, mais diretos e menos preocupados com o outro. Isto acontece não porque o outro sujeito é desconsiderado ou não percebido, mas porque o sujeito com autismo não compreende o significado do ritual que realizamos nas nossas interações sociais habituais. Um outro aspecto que chama a atenção na interação social de pessoas com autismo é que existe sempre um interesse obsessivo por objetos ou frases prontas. Estes parecem atuar como skills (esquemas) de comunicação, que os sujeitos desenvolvem para iniciar uma conversa ou uma interação com alguém. Levando em conta este aspecto, talvez seja interessante desenvolver ambientes digitais adaptados com skills que possam ser criados para os sujeitos com autismo utilizarem como instrumentos de mediação na sua interação social.

Com relação à interação mediada por ferramentas assíncronas, gostaríamos de destacar as seguintes colocações que consideramos relevantes no presente estudo:

1. Não importavam quais fossem as respostas dos interlocutores, os sujeitos com autismo, em geral, continuavam insistindo num único assunto, principalmente enquanto não agiam como agentes intencionais. $\mathrm{Na}$ medida que alguns deles foram se tornando agentes intencionais descentraram-se dos seus interesses e fixações considerando o outro como agente intencional de acordo com os pressupostos estudados.

2. Em alguns momentos foi possível perceber certa afetividade nas mensagens e interesse pelo outro.

3. A interação através de ferramentas assíncronas mostrou ser oposta à interação face-a-face nos sujeitos. Como exemplo podemos citar o caso de M., que presencialmente falava e interagia com as pessoas através de perguntas, na utilização de e-mail comportou-se ignorando as falas do seu interlocutor, centrando-se num único aspecto da comunicação, mantendo um nível de participação passivo-reativo, uma interação hiperformal, mas passiva também. Já A. que se mostrava mais isolado nas interações face-a-face, na interação assíncrona mostrou-se ativo com iniciativa própria e autonomia, mantendo uma comunicação assídua.

4. Os sujeitos com autismo apresentaram nas ferramentas assíncronas as mesmas dificuldades no uso de pronomes e perspectiva referencial, o que pode indicar problemas na tomada de consciência da troca de papéis.

5. Pudemos perceber uma relação entre abreviação predicativa e perspectiva referencial, pois enquanto a abreviação predicativa foi diminuindo, houve um aumento real da perspectiva referencial. Essa co-relação está também relacionada com o nível de partici- pação e interação, como apresentamos nos quadros anteriores.

Com relação à interação mediada por ferramentas síncronas, destacamos as seguintes colocações:

1. O foco das interações manteve-se nas obsessões e fixações. Principalmente se não conheciam os seus interlocutores.

2. Ficou evidente que pessoas com autismo apresentam dificuldade no uso de pronomes também em interações síncronas. Porém, o uso de frases curtas e sem pontuação não interferia na inferência do significado.

3. Alguns sujeitos não se dirigiam a um interlocutor em especial, senão que agiam como se dialogassem com uma platéia. Apresentando alto nível de abreviação predicativa e de ecolalia nas interações síncronas. A ecolalia em algumas oportunidades mostrou-se funcional, como solicitação ajuda ou tentativa de manter uma interação iniciada pelo outro.

4. Em geral, não conseguiam diferenciar corretamente a alternância de papéis e trocas nos diálogos, o que pode explicar o uso da abreviação predicativa ecolálica como uma forma de dar continuidade ao diálogo.

Finalmente, gostaríamos de destacar que o uso do computador e em especial de ambientes digitais de aprendizagem adaptados aos interesses e necessidades dos sujeitos mostraram-se relevantes e importantes no desenvolvimento e na promoção da interação social das pessoas com autismo. $\mathrm{O}$ uso de ambientes digitais como instrumentos de mediação da interação social mostrou-se importante para o desenvolvimento de sujeitos com autismo que apresentaram melhorias ao longo da pesquisa na qualidade da sua interação. Mas a mera inserção da tecnologia não é suficiente para promover essas mudanças, é necessário estabelecer estratégias para serem aplicadas em diferentes ambientes educativos de forma que a inserção da tecnologia possa acrescentar o diferencial qualitativo na promoção da interação social de sujeitos com autismo.

\section{Referências}

Baron-Cohen, S. (1990). Autismo: Uma alteração cognitiva específica de "cegueira mental”. Revista Portuguesa de Pedagogia, 24, 407-430.

Barth, C., Passerino, L., \& Santarosa, L. M. C. (2004, oct.). Software Descobrindo Emoções: Estudo da teoria da mente em autistas. Trabalho apresentado no VII Congresso Iberoamericano de Informática Educativa, Monterrey, México. Retirado em 2004, de http://www.niee.ufrgs.br/ribie2004/Trabalhos/ Comunicacoes/com600-609.pdf

Bosa, C. (2002). Atenção compartilhada e identificação precoce no autismo. Psicologia: Reflexão e Crítica, 15(1), 77-88.

Center for Spoken Language Research at the University of Colorado. (2003). Summer pilot project for children with autism spectrum disorders. Retirado em ago. 2003, de http:// cslr.colorado.edu/beginweb/autism/autism_spectrum.html

Garton, A. (1994). Interacción social y desarrollo del lenguaje y la cognición. Barcelona, España: Paidós. 
Gil, A. B., \& Orts, B. (2003). INMER: Sistema de inmersión en realidad virtual para personas con autismo. Trabalho apresentado em Jornadas de Verano 2003 sobre Tecnologias de Ayuda en alumnos con Necesidades Educativas Especiales, Universidad de Valencia, España. Retirado em ago. 2003, de http://acceso3.uv.es/jornadas2003/charlas.htm

Gutierrez, G. H. (1999). Realidad virtual para personas con autismo. Trabalho apresentado no V Congresso de Autismo-Europa, Madrid, España, 1999. Retirado em abr. 2000, de http:// aut.tsai.es/scripts/articulos/slista

Hanson et al. (2005). Improving Web accessibility trough an enhaced open-source browser. IBM System Journal, 44(3). Retirado em abr. 2005, de http://www-3.ibm.com/able

Heinman, M., \& Tjus, T. (1999). The use of multimedia computer procedures to facilitate language growth among children with autism. Trabalho apresentado no V Congresso de AutismoEuropa, Madrid, España, 1999. Retirado em abr. 2000, de http:/ /aut.tsai.es/scripts/articulos/slista

Hobson, P. R. (1993). El autismo y el desarrollo de la mente. Madrid, España: Alianza.

International Business Machines. (n.d.). IBM and EPFL join forces to uncover the secrets of cognitive intelligence. Retirado em jun. 2005, de http://www-3.ibm.com/able

Jonassen, D. et al. (1999). Learning with technology: A constructivist perspective. Englewood Cliffs, NJ: Prentice Hall.

Jordan, R., \& Powell, S. (1995). Understanding and teaching children with autism. West Sussex, England: John Wiley \& Sons.

Orlich, F. (2003). KidTalk: An innovative model for the delivery of the social skills therapy for children and adolescents with Asperger Syndrome. In University of Washington. Autism Center. Washington, DC: University of Washington. Retirado em ago. 2003, de http://depts.washington.edu/uwautism/ kidtalk.html

Passerino, L. M. (2005) Pessoas com autismo em ambientes digitais de aprendizagem: Estudo dos processos de interação social e mediação. Tese de Doutorado não publicada, Curso de Pós-Graduação em Informática na Educação, Universidade Federal do Rio Grande do Sul, Porto Alegre, RS.

Passerino, L. M., \& Santarosa, L. M. C. (2004, mar.) EDUKITO: Propiciando a inclusão digital de pessoas com necessidades educacionais especiais. RENOTE - Revista de Novas Tecnologias na Educação, 2(1). Retirado em 2004, de http:// www.cinted.ufrgs.br/renote/mar2004/artigos/36-edukito.pdf
Picard, R. W. (2000) Toward computer tht recognize and respond to user emotion. IBM System Journal, 39(3/4). Retirado em abr. 2003, de http://www-3.ibm.com/able

Piconi, A., \& Tanaka, E. (2002, ago.). O uso do HagáQuê por alunos autistas. Trabalho apresentado no III Congresso Internacional de Informática na Educação Especial CIIEE 2002, Fortaleza, CE.

Sigman, M., \& Capps, L. (2000). Niños y niñas autistas: Bruner. Madrid, España: Morata.

Smolka, A. L. B. (2000, abr.). O (im)próprio e o (im)pertinente na apropriação das práticas sociais. Cadernos CEDES, 2O(50), 26-40.

Stake, R. E. (1999). Investigación con estudio de caso. Madrid, España: Moratas.

Silver, M., \& Oakes, P. (2001). Evaluation of new computer intervention to teach people with autism or Asperger syndrome to recognize and predict emotion in others. Sage Publications and The Nacional Autistic Society, 5(3) 299-316.

Tomasello, M. (2003). Origens culturais da aquisição do conhecimento humano. São Paulo, SP: Martins Fontes.

Vygotsky, L. S. (1998). Formação social da mente (6. ed.). São Paulo, SP: Martins Fontes.

Vygotsky, L. S. (2001). A construção do pensamento e da linguagem. São Paulo, SP: Martins Fontes.

Watzlawick, P., Beavin, J. H., \& Jackson, D. D. (1967). Pragmática da comunicação humana: Um estudo dos padrões, patologias e paradoxos da interação. São Paulo, SP: Cultrix.

Wertsch, J. (1988). Vygotsky y la formación social de la mente: Cognición y desarrollo. Barcelona, España: Paidós.

Wertsch, J. (1999). La mente en acción. Buenos Aires, Argentina: Aique.

Wing, L. (1998). El Autismo en niños y adultos: Una guía para la família. Buenos Aires, Argentina: Paidós. 